Original paper

\title{
Community Resilience and Crime Prevention: Applying the Community Engagement Theory to the Risk of Crime
}

\author{
Wendy Schreurs ${ }^{1}$, José, H. Kerstholt ${ }^{12}$, Peter. W. de Vries ${ }^{12}$ and Ellen Giebels ${ }^{1}$
}

Received: 12/08/2019 / Accepted: 20/02/2020 / Published online: 18/05/2020

\begin{abstract}
Citizens are increasingly expected to take a more participatory role in society, which increases the need for them to be knowledgeable about a wide range of uncertain risks and to properly prepare themselves in case these risks become reality. To date, most attention regarding risk preparedness has focused on natural hazards. In the past decade, however, human-made safety risks have gained notoriety in the public's eye. The purpose of this paper is to examine whether the psychological drivers on an individual, community and institutional level of the Community Engagement Theory also apply to the context of social safety hazards such as crime. The study was conducted via an online survey. In total, 1245 Dutch citizens who were already a member of the citizen panel of their municipality at the time of data collection participated in the online study. The results of this research show that the Community Engagement Theory is not only applicable for natural hazards, but also for human-made risks such as crime. Psychological drivers of all three levels, individual, community, and marginally institutional level, are relevant in explaining the willingness to report and intervene when witnessing a crime. This research gives insight and guidance for policy makers and practitioners regarding stimulating reporting and intervening behavior of crime, and citizens information-gathering.
\end{abstract}

Key words: Crime, Reporting behavior, Information gathering, Community Engagement Theory

\section{INTRODUCTION}

Citizens are increasingly expected to take a more participatory role in society, requiring them to act as caregivers, prevent and help solve crime, and mitigate the consequences of hazards and disasters. In the context of public safety, this shift towards a shared responsibility between the government and citizens increases the need for the latter to be knowledgeable

\footnotetext{
1 University of Twente Drienerlolaan 57522 NB

2 TNO
} 
about a wide range of uncertain risks and to properly prepare themselves in case these risks become reality (Yetano et al., 2010). In the Netherlands, for example, citizens living in areas below sea level need to prepare themselves for a serious flooding, as a quick evacuation will probably not be feasible in such a situation (Kerstholt et al. 2017).

To date, most attention regarding risk preparedness has focused on hazards such as floods, tsunami's and earthquakes. In the past decade, however, social safety disasters have gained notoriety in the public's eye. The 9/11 terrorist attacks, and the more recent terrorist attacks near Christmas markets in Berlin in 2016 and Strasbourg in 2018, for instance, have had their impact throughout the Western world (Haridakis and Rubin, 2005), and the same can be said for other human-made risks, such as those pertaining to technological hazards, cybercrime, organized crime, and crime undermining local authority and interfering in businesses (RIVM 2016). These types of crimes have disruptive effects on individuals and communities alike. Terrorist attacks, for example, may strike fear in the heart of citizens (Haridakis and Rubin 2005), and affect the community by pitching groups within societies against each other. Crime undermining local authority may have disastrous consequences for the regular economy and the quality of society (Broekhuizen et al. 2018). Criminal money invested in legitimate businesses may for example result in unfair competition, and drug shacks, hemp plantations and synthetic-drug laboratories may pose physical risks in the form of nuisance, noise, fire, and chemical spillage (Lam et al. 2018). Taken together, it is increasingly realized that crime risks can have severe negative and dislocating effects on the community, stressing the importance of making communities resilient to crime. For the scope of this research, we define a community as 'a group of people with diverse characteristics who are linked by social ties, share common perspectives, and engage in joint action in geographical locations (MacQueen, et al., 2001; e.g. in this context the neighborhood they live in).

Since most citizens would know the ins and outs of their own neighborhood, they would be the most likely candidates to know where criminal activities are likely to happen and to actually recognize crime in action. As such, they can have a valuable role in crime prevention and as sources of crime-related intelligence for the police (Terpstra 2009, Bullock and Sindall 2014). In the past decade, governments have increasingly pursued opportunities for citizen engagement and citizens, in turn, have become more aware of possibilities to actively participate (Yetano et al. 2010). These developments are perhaps best signified by the increase in a number of so-called online neighborhood watches in the Netherlands*. Often involving both citizens and police officers, these online neighborhood watches provide an online means to connect people with the aim to prevent crime and increase crime-solving rates by signaling suspicious activities in their neighborhood (Schreurs, Franjkić, Kerstholt, De Vries \& Giebels (2020), WABP 2018, Pridmore et al. 2018, Lub 2016). This greater

\footnotetext{
* Online neighborhood watches are a rising phenomenon in The Netherlands. This is a type of citizen participation in the social safety domain. Neighbors start groups via the application WhatsApp in order to prevent and detect crime in their neighborhood. These groups are mostly used to report incidents or suspicious circumstances to their neighbors. The group generally has administrators (e.g. neighbors who started the group) who regulate communication via groups. In some cases, the neighborhood police officer is also a member or in contact with the group administrators. The groups differ in how professional they are set up, and vary in the amount of members (from covering inhabitants living in one street up to an entire block; Schreurs, et al., 2020; Mehlbaum \& Van Steden, 2018; WABP 2018).
} 
demand on citizens to partake in the fight against crime on the one hand, and the increasing opportunities for them to do so on the other, underscores the importance to know which psychological factors drive people to actually take these opportunities.

Multiple well-known psychological theories have been developed to predict citizens' preparatory and adaptive behavior for hazards and disasters, for example the Protective Action Decision Model and the Protection Motivation Theory (Terpstra 2011; Lindell \& Perry 2012; Floyd, Prentice-Dunn \& Rogers 2000). These theories, however, mainly address individual- and social-related factors. Another theory aiming to predict citizens' preparatory behavior, called the Community Engagement Theory (Paton, 2013; Paton et al. 2008), takes into account institutional-related drivers as well. This theory proposes that individual beliefs, social network characteristics in the community, and the relationship between community and institutions influence the extent to which citizens are willing to receive information and to use this information to prepare for hazards. The Community Engagement Theory has been described as an all-hazard theory: it has been validated for disasters such as floods, tsunamis, and earthquakes, and across different cultures (Paton et al. 2013). To date, however, the domain of application has not been extended beyond the context of natural hazards; consequently, applicability to social safety risks such as crime has yet to be assessed. Furthermore, as far as we know, no research has been conducted in the social safety domain which has examined individual, community, as well as institutional factors simultaneously. While it is expected that all three perspectives would be relevant to citizen participation in the social safety domain, as it can be performed individually, in collaboration with other citizens (e.g., neighbors or bystanders) and/or in collaboration with the police. In the present study, it will therefore be examined whether the psychological drivers on an individual, community and institutional level of the Community Engagement Theory also apply to the context of social safety hazards such as crime.

\section{Applying the Community Engagement theory to the risk of crime}

According to Paton (2013), dealing with uncertainty represents a common denominator in people's experience of various hazardous events. In the example of a flooding, citizens may be uncertain about the exact time and place of the flooding, its intensity, and its potential consequences (Kerstholt et al. 2017). Taking preparatory action can be seen as a means to cope with these uncertainties. This should be no different from the risk of becoming a victim of crime: whether or not citizens would become a victim of crime is highly uncertain, as is the severity of the crime itself and its consequences for individuals and their community.

Obviously, exactly which specific preparatory actions are required would depend on the nature of the risk. For an earthquake, these actions can for example consist of protecting your house to avoid that it collapses during an earthquake and stock up on food and water (Paton et al. 2010), whereas for a flooding one could acquire an emergency kit or knowledge on how to evacuate or where safe locations can be found (Kerstholt et al. 2017). These preparatory behaviors aim to mitigate negative consequences in case the specific risk occurs. For crime, mitigation may involve reporting a suspicion of crime to the police through the correct 
channels or discussing such suspicions with neighbors. Preparations would then be to get information on how to act when a crime occurs, for example, how to report to the police, using which channels, or how to intervene.

Crime is a special domain in comparison to the domain of natural hazards, in the sense that the police has a monopoly on violence. In crime prevention, citizens are not free to do anything they want, but are bounded by laws and regulations. This emphasizes the relevance of relationships between citizens and institutions as the police: collaboration between the former and the latter should ensure that citizens abide by these rules and do not take the law into their own hands. However, citizens increasingly act out of their own initiative, do not always seek contact with the police, and do not always adhere to these rules or regulations. A government's vision of a greater citizen participation in the fight against crime may therefore increase the risk that this participation turns into vigilantism, where citizens, for example, use unauthorized violence or violate the privacy rights of the suspect (Haas et al. 2014, Lub and De Leeuw 2019). Ideally, therefore, citizens should not act fully independently. Police officers, or the police as an organization, should assist citizen participation by informing them about the relevant laws and regulations, and provide some oversight to ensure these are abided by. For example, a burglary in progress should be stopped by citizens calling in the help of the police, rather than apprehending the suspect themselves, and, perhaps, use violence (Jackson et al. 2013).

All in all, it could be argued that the Community Engagement Theory's all-hazard applicability would also apply to how people make choices in actual information gathering and whether they are willing to act when crime occurs (for example by reporting to the police and intervening when witnessing a crime).

\section{Psychological drivers}

The Community Engagement Theory takes into account psychological drivers on three levels, the individual, community and institutional level.

\section{Individual level}

The individual level includes beliefs regarding the hazard, as well as regarding the appropriate preventive or responsive behavior. Risk perception is one of these individual drivers. Operationalized as the perceived likelihood of the risk to occur and the perceived severity of the consequences (Paton et al. 2008), a higher risk perception has been shown to lead to more information seeking (Ter Huurne and Gutteling 2008).

Previous research on preparatory behavior for hazards has shown that whether people see themselves as capable to perform the specific behavior, also known as self-efficacy, will influence whether they will actually perform that behavior. Besides self-efficacy, also response efficacy (also called outcome expectancy), i.e. the belief, whether the advised behavior will have the anticipated effect, is expected to increase preparatory behavior (Paton 
2013, Floyd et al. 2000). A previous study in the context of crime, specifically on membership of an online neighborhood watch, for example, showed that citizens who believed that joining such a group would lead to a reduction of crime were more likely to become a member of an online neighborhood watch (Authors Manuscript submitted for publication). Additionally, information in risk communication perceived as high in selfefficacy and response efficacy increases the likelihood that citizens prepare themselves for flood risk (Kievik and Gutteling 2011).

In the police domain, and in crime prevention specifically, morality plays an essential role (Cromby et al. 2010). In order for citizens to report crime or intervene, they first have to decide whether they classify certain behavior they have witnessed, for instance, someone stealing a bicycle, as right or wrong (Harkness and Hitlin 2014). Experiencing a conflict with their moral values, then leads to the experience of moral emotions such as anger or disgust (Haidt 2003), in turn motivating behavior such as reporting the crime to the police. Further, previous research has shown that the experience of negative emotions (for example fear) will influence people's eagerness to gather information about a risk and courses of action (Nabi 2003). In the case of crime, this information could be about courses of action regarding reporting crime to the police or intervening when being a witness of crime. Hence, for the purpose of this study morality was added to the individual level in the form of moral values and moral emotions.

\section{Community level}

On the community level, the Community Engagement Theory takes several drivers into account. The first one is a citizen's sense of community, entailing to what extent they feel connected with their neighborhood (Ohmer and Beck 2006, Paton and Johnston 2001). Second, citizens may also experience a certain degree of collective efficacy, meaning that citizens feel that they are capable as a community to perform a certain action (Ohmer and Beck 2006, Hipp 2016), for instance, to protect the community against crime. Third, whether citizens have participated in their community on a broad range of domains in the past (e.g., organized a street barbecue, attending public meetings or joined a neighborhood crime watch) is expected to increase the likelihood of reporting and intervening behavior when the occasion arises. By participating in the community, citizens engage in social contacts, making it easier to gather information on how to act. This in turn might increase confidence to act again in the future (Paton et al. 2013).

\section{Institutional level}

In crime prevention, the institutional level is just as, or maybe even more, important than in the case of a natural hazard. When acting on criminal activity in their neighborhood, citizens may either directly contact the police, or are very likely to encounter the police in the process. Additionally, citizens are probably more likely to assist the police by intervening or report a crime to them when they trust the police (Stoutland 2001, Jackson and Bradford 2010, 
Bradford, Sargeant, Murphy, \& Jackson, 2017), and see the police as a legitimate authority (Tyler and Fagan 2008, Jackson et al. 2013). Finally, according to the Engagement Community Theory, citizens are more likely to engage in the public domain when they feel empowered. This means that when citizens feel that they have influence on (local) government policy and that their opinions are heard by the local governments, they are more likely to participate in the public domain (Paton 2013), e.g., by reporting crime to the police or by citizen intervention.

\section{Present study}

In the present study, it will be examined whether the Community Engagement Theory also applies to the context of a human-made risk, namely to the risk of being exposed to crime. This paper investigates the relation between psychological drivers on the individual, community and institutional level with 1) actual information gathering about how to report to the police and how to be able to intervene as a community (as a way to measure preparatory behavior), and 2) the willingness to act if crime did occur to them or in their neighborhood (as a way to measure intentional behavior after the risk has occurred).

\section{METHOD}

\section{Participants and procedure}

In total, 1245 Dutch citizens participated in the online survey. They were asked to participate through the citizen's panel of three municipalities located in the south of The Netherlands. Participants were already members of the citizen panel of their municipality at the time of data collection, and received an email whether they would like to participate in an online study on reporting and intervening behavior regarding crime in their neighborhood. The response rate across municipalities was $18.7 \%$.

The survey started with asking for informed consent and some demographic questions regarding age, gender, and education. After this they filled in questions regarding psychological variables on the three levels of the Community Engagement Theory. Next, participants filled in questions regarding their willingness to act on crime in the future. They were not given a particular type or seriousness of crime, as it was supposed to be a general willingness to act on crime occurring in their neighborhood. Participants were asked which type of crime they thought of when answering these questions about their willingness to act. Main crimes mentioned were burglary, drug related crime, vandalism, theft and arson. Also, some additional questions regarding membership of neighborhood-WhatsApp groups and open questions regarding their motivations to act were asked. However, since they provided no additional information, they will not be elaborated upon in this paper. At the end of the survey, actual information gathering was measured by asking participants whether they were willing to receive information regarding how to report to the police and how to organize 
themselves in a neighborhood-WhatsApp group. When they agreed, they actually received the information.

\section{Measures}

\section{Dependent variables}

Actual information gathering was measured by asking participants whether they were willing to receive information regarding how to report crime and how to organize themselves in a neighborhood WhatsApp group. Their answers were recoded into "no" (not willing to receive any information; coded as 1) and "yes" (willing to receive information about reporting and intervening; coded as 2 ). When they wanted to receive information, participants actually received links to the information. Because of constraints on lengths imposed by one of the municipalities this variable was only asked in two of three municipalities $(\mathrm{N}=762)$.

Willingness to report and intervene was measured by asking participants whether they were willing to act themselves in crime situations. Participants reported to what extent the following four items were applicable to them; "I would call the police when I witness crime", "I would discuss suspicious circumstances with a police officer", "If I were to witness a crime, I would be inclined to intervene to try to stop the offender" and "Together with my neighbors, I would take the initiative to prevent crime in my neighborhood" (scale $1=$ not at all applicable, $5=$ very applicable, $\alpha=.70$ ).

\section{Independent variables}

All independent variables described below were measured on a 5-point Likert-scale, unless described otherwise. They were all based on the items used in the Community Engagement Theory (Paton, 2013), except for the construct of 'moral values' and 'negative emotions'. The items were adapted to the context of social safety (e.g. the focus of risk perception was on crime instead of on a natural hazard, and efficacy focused on the ability to create a safer neighborhood, and organizing as a community in order to prevent crime).

\section{Individual level}

Risk perception was measured by asking participants how likely they thought it was that crime took place in their neighborhood (Crime Likelihood, five statements, $\alpha=.87$, e.g. "How likely is it that crime is taking place in your neighborhood?") and that crime would lead to certain consequences (Crime Consequences, five statements, $\alpha=.86$, e.g. "How likely is it that crime will result into major damage to your house/possessions?"; Paton et al. 2008).

Moral values were measured by asking participants how important they felt that specific moral values, as defined in a study by Steg et al. (2014), were guiding principles in their live (scale: 1 - not important, 7 = very important). The values consisted of altruistic (four statements, $\alpha=.76$, e.g. "social justice", "helpful", "a world at peace" and "equality") and 
egoistic values (five statements, $\alpha=.73$, e.g. "wealth", "social power", "influential", "ambitious", "authority").

Negative emotions were measured by asking respondents how they felt when thinking about the possibility of crime taking place in their neighborhood. Respondents were specifically asked for four emotional states (four statements, $\alpha=.89$, e.g. "afraid", "worried", "angry", and "furious").

Self-efficacy was measured by asking respondents how much they perceived themselves to be capable of contributing to a safer neighborhood (six statements, $\alpha=.82$, e.g. "I know how to report crime to the police" and "I consider myself capable to prevent crime in my neighborhood").

Response efficacy was measured by asking participants to what extent they thought specific measures they could take would be effective (six statements, $\alpha=.78$, e.g. "participating in a neighborhood-WhatsApp group promotes the safety in my neighborhood").

\section{Community level}

Sense of community was measured by giving participants statements regarding their connection with the neighborhood (eight statements, $\alpha=.91$, e.g. "I feel connected with the people in my neighborhood").

Collective efficacy was measured by asking to what extent they perceived that they were able to solve problems in collaboration with other neighbors (six statements, $\alpha=.85$, e.g. "In difficult situations, as a neighborhood, we are able to work together on a solution").

Community participation was measured by asking participants about their previous experience with a broad range of community participation as well as regarding reporting and intervening behavior specifically (nine statements, $\alpha=.81$, e.g. "I attend neighborhood activities such as a neighborhood barbecue or party", and: "I have called the police in the past to report crime").

\section{Institutional level}

Trust in the police was measured by asking participants to what extent they trusted the police based on Stoutland (2001) and Bradford, et al. (2017; nine statements, $\alpha=.93$, e.g. "you can trust the police when you need them" and "the police does everything it can to prevent crime").

Police legitimacy was measured based on previous research of Tyler and Fagan (2008). Reliability score was relatively low $(\alpha=.66)$, a factor analysis showed that taking only the positively framed items into account had a higher reliability (five statements, $\alpha=.89$, e.g. "In general, the police are a legitimate authority and people have to obey the decision of police 
officers" and "You have to do what the police tell you to do, even if you do not like the way they treat you".)

Empowerment was measured by asking participants to what extent they felt they could have influence on what happened in their neighborhood on an institutional level, and was based on research of Paton (2013; eight statements, $\alpha=.80$, e.g. "Voting in local elections affects what is being dealt with in the neighborhood" and "I believe that elected representatives take my opinion seriously").

\section{RESULTS}

\section{Descriptive statistics and correlations}

Means, standard deviations and correlations for the dependent and independent variables are shown in Table 1. As we had a large sample, we tested for multicollinearity between independent variables. This was not the case, as all VIF's were below 3 (while below 5 is recommended) and tolerance levels were above 0.2 (Ringle et al. 2015). In total, $55.7 \%$ of participants were willing to receive information. The willingness to receive information (no = 1 ; yes $=2$ ) was positively correlated with risk perception - crime consequences $(r=.13, p$ $<.01)$, risk perception - crime likelihood $(r=.13, p<.01)$, negative emotions $(r=.14, p$ $<.01)$, altruistic values $(r=.12, p<.01)$, egoistic values $(r=.07, p<.05)$, collective efficacy $(r=.09, p<.05)$ and previous community participation $(r=.09, p<.05)$, and negatively correlated with trust in the police $(r=-.08, p<.05)$. Whether citizens were willing to report and intervene, correlated positively with altruistic values $(r=.14, p<.01)$, egoistic values ( $\mathrm{r}$ $=.08, p<.01)$, self-efficacy $(\mathrm{r}=.36, \mathrm{p}<.01)$, response efficacy $(r=.44, p<.01)$, sense of community $(r=.22, p<.01)$, collective efficacy $(r=.33, p<.01)$, past community participation $(r=.37, p<.01)$, trust in the police $(r=.35, p<.01)$, police legitimacy $(r=.19$, $p<.01)$ and empowerment $(r=.23, p<.01)$. The municipality correlated with the willingness to receive information $(r=-.08, p<.05)$. 
Table 1. Means, standard deviations, reliabilities and intercorrelations among the variables

\begin{tabular}{|c|c|c|c|c|c|c|c|c|c|c|c|c|c|c|c|c|c|}
\hline Variables & $\mathrm{M}$ & SD & 1 & 2 & 3 & 4 & 5 & 6 & 7 & 8 & 9 & 10 & 11 & 12 & 13 & 14 & 15 \\
\hline $\begin{array}{l}\text { 1. Actual information } \\
\text { gathering }\end{array}$ & 1.56 & .50 & - & & & & & & & & & & & & & & \\
\hline 2. Willingness to act & 2.83 & .90 & $.10 * *$ & - & & & & & & & & & & & & & \\
\hline $\begin{array}{l}\text { 3. Risk perception - } \\
\text { Crime consequences }\end{array}$ & 3.08 & .83 & $.13 * *$ & .01 & - & - & & & & & & & & & & & \\
\hline $\begin{array}{l}\text { 4. Risk perception - } \\
\text { Crime likelihood }\end{array}$ & 2.81 & .87 & $.13^{* *}$ & -.02 & $.67 * *$ & - & & & & & & & & & & & \\
\hline 5. Negative emotions & 2.55 & .98 & $.14 * *$ & -.01 & $.52 * *$ & $.56^{* *}$ & - & & & & & & & & & & \\
\hline 6. Altruistic valuesb ${ }^{\mathrm{b}}$ & 6.00 & .91 & $.12 * *$ & $.14 * *$ & $-.06^{*}$ & -.05 & $-.07 *$ & - & & & & & & & & & \\
\hline 7. Egoistic valuesb ${ }^{b}$ & 3.56 & 1.04 & $.07 *$ & $.08 * *$ & $.06^{*}$ & $.07 *$ & $.16^{* *}$ & -.02 & - & & & & & & & & \\
\hline 8. Self efficacy & 3.34 & .68 & -.08 & $.36 * *$ & -.05 & $-.12 * *$ & $-.11 * *$ & $.09 * *$ & $.13^{* *}$ & - & & & & & & & \\
\hline 9. Response efficacy & 3.28 & .67 & .07 & $.44 * *$ & $-.23 * *$ & $-.23 * *$ & $-.23 * *$ & $.20 * *$ & $.10 * *$ & $.37 * *$ & - & & & & & & \\
\hline 10. Sense of community & 3.59 & .74 & .07 & $.22 * *$ & $-.22 * *$ & $-.19 * *$ & $-.15^{* *}$ & $.16^{* *}$ & $.13 * *$ & $.20 * *$ & $.30^{* *}$ & - & & & & & \\
\hline 11. Collective efficacy & 3.31 & .62 & $.08 *$ & $.33 * *$ & $-.17 * *$ & $-.14 * *$ & $-.15^{* *}$ & $.20 * *$ & $.15^{* *}$ & $.26^{* *}$ & $.40^{* *}$ & $.54 * *$ & - & & & & \\
\hline 12. Community participation & 2.32 & .73 & $.09 *$ & $.37 * *$ & $.24 * *$ & $.12 * *$ & $.20 * *$ & .01 & $.17 * *$ & $.25^{* *}$ & $.17 * *$ & $.26^{* *}$ & $.34 * *$ & - & & & \\
\hline 13. Trust in the police & 3.21 & .73 & $-.08^{*}$ & $.35 * *$ & $-.27 * *$ & $-.25 * *$ & $.27 * *$ & $.21 * *$ & .03 & $.25^{* *}$ & $.76^{* *}$ & $.30 * *$ & $.34 * *$ & $.08 * *$ & - & & \\
\hline 14. Police legitimacy & 3.57 & .73 & -.01 & $.19 * *$ & $-.09 * *$ & $-.08 * *$ & -.05 & .05 & $.09 * *$ & $.10^{* *}$ & $.28 * *$ & $.12^{* *}$ & $.14^{* *}$ & $.12^{* *}$ & $.41^{* *}$ & - & \\
\hline 15.Empowerment & 3.10 & .71 & .07 & $.23 * *$ & $-.16^{* *}$ & $-.17 * *$ & $-.18 * *$ & $.20 * *$ & $.10^{* *}$ & $.18^{* *}$ & $.43^{* *}$ & $.29^{* *}$ & $.45^{* *}$ & $.19^{* *}$ & $.46^{* *}$ & $.23^{* *}$ & - \\
\hline 16. Age & 59.76 & 12.34 & $.18 * *$ & .00 & .01 & .01 & .04 & $.08 *$ & .01 & -.06 & -.01 & $.10^{* *}$ & .00 & .01 & .03 & $-.09 * *$ & -.01 \\
\hline 17. Gender ${ }^{\mathrm{c}}$ & 1.39 & .49 & -.02 & -.05 & -.01 & .03 & .02 & -.08 & $-.13 * *$ & $-.12 * *$ & .01 & -.02 & .03 & $-.08 * *$ & $.07 *$ & $-.06^{*}$ & .04 \\
\hline 18. Education & $\mathrm{n} / \mathrm{a}$ & $\mathrm{n} / \mathrm{a}$ & -.01 & .00 & .00 & -.07 & $-.13 * *$ & .03 & -.05 & .02 & .02 & -.03 & .04 & $.10^{* *}$ & .02 & .03 & $.16^{* *}$ \\
\hline 19. Years in neighborhood & 21.47 & 13.72 & $.09 *$ & -.05 & .01 & .00 & -.00 & -.03 & .00 & -.02 & -.04 & $.12 * *$ & -.06 & .01 & .01 & -.06 & -.11 \\
\hline 20. Municipality & $\mathrm{n} / \mathrm{a}$ & $\mathrm{n} / \mathrm{a}$ & $-.08 *$ & .06 & .00 & $.23 * *$ & $.19 * *$ & -.01 & $.07 *$ & $.07 * *$ & $-.08 * *$ & $.06^{*}$ & .03 & .05 & $-.12 * *$ & $-.10 * *$ & .03 \\
\hline
\end{tabular}

Note. ${ }^{*} p<.05, * * p<.01,{ }^{a} 1=N o, 2=Y e s,{ }^{b}$ measured on a 7 -point scale (opposed to a 5-point scale), ${ }^{c} 1=$ male, $2=$ female 


\section{Regression analyses}

\section{Actual information gathering}

A multilevel logistic regression analysis was conducted with actual information gathering $(1=$ no, 2 = yes $)$ as dependent variable, the municipality as grouping variable and the psychological drivers as covariates. The results (see Table 2) showed that Risk perception crime likelihood $(\beta=.40, p=.003)$, negative emotions $(\beta=.29, p<.01)$ and altruistic values $(\beta=.24, p<.01)$ were positive predictors and self-efficacy $(\beta=-.43, p<.01)$ was a negative predictor for the willingness to gather information. Egoistic values were marginally significant $(\beta=.13, p=.083$ ). The variance between municipalities was not significant $(\mathrm{p}=.62)$, and the accuracy rate of predicting information gathering was $62.2 \%$

Table 2. Multilevel binary logistic regression analysis of psychological drivers on actual information gathering about how to report and organize as a community to prevent crime $(\mathrm{No}=1$, $\mathrm{Yes}=2)$, with municipality as grouping factor

\begin{tabular}{llllll}
\hline Variable & $\mathrm{B}$ & $\mathrm{S} . \mathrm{E} . \beta$ & $\mathrm{t}$ & $p$ & Exp (B) \\
\hline Risk perception - & -.20 & .13 & -1.62 & .105 & 0.82 \\
Crime consequences & & & & & \\
Risk perception - & .40 & .13 & 2.95 & .003 & 1.49 \\
Crime likelihood & .29 & .10 & 2.85 & .005 & 1.34 \\
Negative emotions & .24 & .09 & 2.71 & .007 & 1.28 \\
Altruistic values & .13 & .08 & 1.74 & .083 & 1.14 \\
Egoistic values & -.43 & .13 & -3.34 & .001 & 0.65 \\
Self-efficacy & .12 & .19 & 0.64 & .523 & 1.13 \\
Response efficacy & .11 & .13 & 0.82 & .410 & 1.11 \\
Sense of community & .12 & .16 & 0.73 & .468 & 1.13 \\
Collective efficacy & .13 & .13 & 1.00 & .318 & 1.13 \\
Community participation & .26 & 0.18 & 1.43 & .153 & 1.30 \\
Trust in the police & -.14 & 0.13 & -1.14 & .255 & 0.87 \\
Police Legitimacy & .04 & 0.13 & 0.33 & .738 & 1.05 \\
Empowerment & & & & & \\
\hline
\end{tabular}

$\mathrm{N}=762$, accuracy rate $62.2 \%$ 


\section{Willingness to act}

A multilevel linear regression analysis was conducted with the willingness to act as dependent variable, the municipality as grouping variable and the psychological drivers as covariates. The results (see Table 3 ) showed that self-efficacy $(\beta=.22, p<.01)$, response efficacy $(\beta=.36, p<.01)$, collective efficacy $(\beta=.13, \mathrm{p}=.01)$ and past community participation $(\beta=.30, p<.01)$ were positive predictors for the willingness to act. Police legitimacy $(\beta=.06, p=.054)$ and trust in the police $(\beta=.09, p=.083)$ were marginally significant. The variance between municipalities was not significant $(p<.50)$. SPSS does not provide an explained variance for multilevel regression analyses, but since the municipalities did not have an effect on the model, a linear regression analyses was conducted which showed the same significant predictors and an $R^{2}$ of .32 .

Table 3. Multilevel linear regression analysis of psychological drivers on the willingness to act, with municipality as grouping factor

\begin{tabular}{lllll}
\hline Variable & B & S.E. $\beta$ & T & $p$ \\
\hline Risk perception - & .03 & 0.03 & 0.77 & .445 \\
Crime consequences & & & & \\
Risk perception - & .03 & 0.04 & 0.74 & .457 \\
Crime likelihood & & & & \\
Negative emotions & .01 & 0.03 & 0.47 & .636 \\
Altruistic values & .04 & 0.02 & 1.61 & .108 \\
Egoistic values & -.03 & 0.02 & -1.23 & .219 \\
Self-efficacy & .22 & 0.04 & 6.32 & .000 \\
Response efficacy & .36 & 0.05 & 6.73 & .000 \\
Sense of community & -.02 & 0.04 & -0.48 & .633 \\
Collective efficacy & .12 & 0.05 & 2.64 & .008 \\
Community participation & .30 & 0.03 & 8.74 & .000 \\
Trust in the police & .09 & 0.05 & 1.74 & .083 \\
Police Legitimacy & .06 & 0.03 & 1.93 & .054 \\
Empowerment & -.05 & 0.04 & -1.33 & .184 \\
\hline N=1245, R ${ }^{2}=.32$ & & & &
\end{tabular}

\section{DISCUSSION}

This study examined whether the Community Engagement Theory by Paton and colleagues would also apply to a human-made risk, specifically to crime. This paper investigated the relation between psychological drivers on an individual, community and 
institutional level with actual information gathering about courses of action and with the willingness to act after being exposed to crime.

Results showed that actual information gathering was only influenced by factors at the individual level, and not by factors at the community and institutional level. On the individual level, risk perception showed to influence information gathering. This result is in line with previous research by Ter Huurne and Gutteling (2008), showing that risk perception has a direct effect on the intention to seek information on chemical transport. The present study showed that this is also the case for the risk of crime occurring. When citizens perceive the likelihood of a crime to occur as higher, they are more likely to gather information about the risk.

Additionally, citizens scoring higher on altruistic values such as social justice, were more often inclined to gather information. This is in line with previous research, in which moral values are generally known to increase moral behavior (Steg et al., 2014, Bardi and Schwartz 2003). When people have high altruistic values, they might be more motivated to help society and gather information on how to mitigate the risk of crime.

Our results did show that when participants experienced more negative emotions (e.g. being afraid and angry), they were also more likely to be willing to receive information. Previous research also showed that in order to cope with these negative emotions, it is likely that the need for information increases, which in turn increases actual information gathering regarding the courses of action about the risk (Nabi 2003). Furthermore, citizens felt less capable to act (lower self-efficacy) were more willing to gather information. Furthermore, when citizens felt less capable in reporting crime and intervening, they are in need of information regarding courses of action of the risk in order to increase their feelings of capability. This corresponds with research of Kievik and Gutteling (2011) showing that when information regarding risk communication is perceived as high in self-efficacy, it increases the likelihood that citizens prepare themselves for flood risk.

The willingness to act was influenced by factors at all three levels, the individual and social level, and marginally by the institutional level. As such our results are in line with Community Engagement Theory and elaborates the applicability of this model to other domains such as crime.

Citizens who felt more capable of reporting and intervening (self-efficacy) were more willing to act when a crime would occur. Interestingly, citizens with a low level of selfefficacy were more willing to receive information, while citizens with higher self-efficacy were more willing to report and intervene. This suggests that it might be useful to provide information which increases people's self-efficacy (Kievik and Gutteling 2011). Further, citizens who believed that reporting and intervening would be effective in fighting crime (response efficacy) increased the willingness to act. This is in line with the Community Engagement Theory on natural hazards (Kerstholt et al. 2017, Paton 2013).

On the community level, citizens with higher beliefs of collective efficacy, meaning that they felt capable as a community to deal with crime, were more willing to report and 
intervene. Also, citizens who had participated more in their community were also more willing to act. This also corresponds with the Community Engagement Theory, as well as with previous research on citizen participation in the police domain (Authors Manuscript submitted for publication, Paton et al. 2013). Reporting and intervening behavior can be seen as a social behavior, citizens might discuss crime with their neighbors before reporting it and by participating on other domains in the neighborhood will increase their social contacts and knowledge, making them feel more confident of being capable to act again in the future.

The institutional level only had a marginal effect, showing that citizens with a higher trust in the police and who saw the police more as a legitimate authority were more willing to report and intervene.

When looking at the difference between informing and acting it can be seen that the first was only influenced by psychological drivers on the individual level, while the latter was influenced by the individual, community and marginally by the institutional level. An explanation could be that seeking and information gathering is typical individual behavior, while reporting and intervening behavior is more related to the community since the crime is probably not only affecting the individual but the community as well. Possibly, people would not like to intervene on their own considering the risks intervening might have (e.g. getting into a fight) but would like to rely on neighbors to help them if necessary. Furthermore, the institutional level did not influence information seeking at all, while it would be expected that at least police legitimacy would have a significant effect, since reporting and intervening behavior is also likely to be linked to the police (Jackson et al. 2013, Gill et al. 2014). It would be recommended in future research to also examine motivations behind the (un)willingness to gather this information. However, these were only marginally significant. One possible explanation is that the level of trust and legitimacy are quite high (means of 3.21 and 3.57 respectively and low in variety (SD's are both .73), which could be due to a bias in the sample via citizen panels. Another explanation could be that low as well as high levels of police legitimacy can increase information gathering and the willingness to act. Citizens feeling high levels of legitimacy might be very motivated to participate with the police by reporting and gathering information how to, while citizens who experience low levels of police legitimacy are more motivated to act on their own and are less interested in collaboration with the police. Future research could look into the role of high and low legitimacy.

Furthermore, this study did not examine causal relations between individual, social and institutional factors, however, correlations do show a pattern that all three levels are interrelated. This does reinforce the notion that all three groups of factors of the Community Engagement Theory are relevant to the context of social safety hazards such as crime. This does reinforce the notion that all three groups of factors of the Community Engagement Theory are relevant to the context of social safety hazards such as crime. Future research is needed to examine exact relationships between these perspectives.

The willingness to receive information and to act only correlated with each other weakly. Since this was not an experimental but a correlational study, based on these results it cannot 
be concluded whether the willingness to report and intervene increases after receiving the information. It would be interesting for future research to examine whether giving citizens information with courses of action would actually increase their willingness to act.

\section{Limitations}

This study does come with some limitations. First of all, this study did not measure actual reporting and intervening behavior, but only the intention. This might have influenced the results. It was expected that when citizens are asked about their intention, they have more time to think about their behavior and make an analytic decision. On the other hand, when they would actually be exposed to crime, more intuitive decision processes, like emotions, would have more weight in the decision to behave in a certain way. However, a measure of actual information gathering behavior was included. Citizens were asked whether they were willing to receive information about how to report crime, after which they actually received this information.

Secondly, for this study existing citizen panels were used to collect data. This might have caused a selection bias, since citizens who are willing to be a member of these voluntary citizen panels are already a selection of more active citizens. This might have increased the willingness to receive information and to report and intervene in the future. Furthermore, the response rate was quite low, which might have led to sampling bias. Nonetheless, we believe that the results of this study, and the application of the Community Engagement theory to the social safety domain can act as a starting point for future research. Although the sample varied broadly in age and the years respondents lived in their neighborhood, in future research it would be recommended to take a more representative sample of society. The main interest of this paper was however to examine the influence of psychological drivers on citizens' willingness, which was possible to do by using this sample.

\section{Practical implications}

The findings of this study give practitioners in the field (i.e. police and municipalities) some insight in the psychological drivers behind reporting and intervening behavior. When institutions want citizens to be informed about how to keep their community safe and how to participate, they should mainly focus on the individual level. For example, by stressing that the information can help to increase feeling capable to act effectively when necessary in order to increase self-efficacy and response efficacy (Kievik and Gutteling 2011). When trying to increase reporting and intervening behavior, the community level is also of importance. One recommendation is to focus on increasing citizen participation in communities, by organizing events and meetings and trying to involve large groups of citizens. When citizens have participated before and have more knowledge about how to report and what to do when they come across suspicious circumstances or crime, they are more likely to participate again in the future. When designing strategies, especially on increasing intervening behavior, it is important to keep in mind that this could also come with some negative effects, such as citizens taken the law into their own hands. 
Concluding, the Community Engagement Theory is not only applicable for natural hazards, but also for human-made risk such as crime. Psychological drivers on all three levels, individual, community, and marginally institutional level, are relevant in explaining the willingness to report and intervene when witnessing a crime. Human-made safety risks are gaining importance in society (such as terrorism, organized crime and crime undermining local authority). As these hazards can have great negative and dislocating effects on the community, it is of extra importance to have insight on the psychological drivers to take preparatory actions, further increasing societal resilience.

\section{REFERENCES}

Bardi, A. and Schwartz, S. H. (2003), "Values and Behavior: Strength and Structure of Relations", Personality and Social Psychology Bulletin, Vol. 29, pp. 1207-1220.

Bradford, B., Sargeant, E., Murphy, K., \& Jackson, J. (2017), A leap of faith? Trust in the police among immigrants in England and Wales. The British Journal of Criminology, Vol. 57(2), pp.381-401.

Broekhuizen, J., Meulenkamp, T., Stoutjesdijk, F. and Boutellier, H. (2018), "Ondermijnende criminaliteit en de meldingsbereidheid van burgers: een pilotonderzoek in drie buurten in Brabant-Zeeland".

Bullock, K. and Sindall, K. (2014), "Examining the nature and extent of public participation in neighbourhood policing", Policing and society, Vol. 24, 3 pp. 85-404.

Cromby, J., Brown, S. D., Gross, H., Locke, A. and Patterson, A. E. (2010), "Constructing crime, enacting morality: emotion, crime and anti-social behaviour in an inner-city community", The British Journal of Criminology, Vol. 50, pp. 873-895.

Floyd, D. L., Prentice - Dunn, S. and Rogers, R. W. (2000), "A meta - analysis of research on protection motivation theory", Journal of applied social psychology, Vol. 30, pp.407429.

Gill, C., Weisbird, D., Telep, C., Vitter, Z. and Bennett, T. (2014), "Community-oriented policing to reduce crime, disorder and fear and increase satisfaction and legitimacy among citizens: a systematic review", Journal of Experimental Criminology, Vol. 10, pp. 399-428.

Haas, N. E., DE Keijser, J. W. and Bruinsma, G. J. (2014), "Public support for vigilantism, confidence in police and police responsiveness", Policing and society, Vol.24, pp. 224-241.

Haidt, J. (2003), "The moral emotions", In: Davidson, R. J., Scherer, K. R. and Goldsmith, H. H. (eds.) Handbook of Affective Sciences, Oxford: Oxford University Press.

Haridakis, P. M. and Rubin, A. M. (2005), "Third-person effects in the aftermath of terrorism", Mass Communication and Society, Vol.8, pp. 39-59. 
Harkness, S. K. and Hitlin, S. (2014), "Morality and Emotions", In: Stets, J. E. and Turner, J. H. (eds.), Handbook of the Sociology of Emotions: Volume II, Springer Netherlands.

Hipp, J. R. (2016), "Collective efficacy: How is it conceptualized, how is it measured, and does it really matter for understanding perceived neighborhood crime and disorder?", Journal of criminal justice, Vol. 46, pp. 32-44.

Jackson, J. and Bradford, B. (2010), "What is Trust and Confidence in the Police?", Policing: A journal of policy and practice, Vol. 4, pp. 241-248.

Jackson, J., Huq, A. Z., Bradford, B. and Tyler, T. R. (2013), "Monopolizing force? Police legitimacy and public attitudes toward the acceptability of violence", Psychology, Public Policy, and Law, Vol. 19, No. 4, pp. 479.

Kerstholt, J., Duijnhoven, H. and Paton, D. (2017), "Flooding in The Netherlands: How people's interpretation of personal, social and institutional resources influence flooding preparedness", International journal of disaster risk reduction, Vol. 24, pp. 52-57.

Kievik, M. and Gutteling, J. M. (2011), "Yes, we can: motivate Dutch citizens to engage in self-protective behavior with regard to flood risks" Natural hazards, Vol. 59, pp. 14751490 .

Lam, J., Van Der Wal, R. and Kop, N. (2018), "Sluipend gif". Politieacademie: Apeldoorn.

Lindell, M. K., \& Perry, R.W. (2012), The protective action decision model: theoretical modifications and additional evidence. Risk Analysis: An International Journal, 32(4), 616-632.

Lub, V. (2016), "De burger op wacht. Het fenomeen 'buurtpreventie'onderzocht".

Lub, V. and De Leeuw, T. (2019), "Politie en actief burgerschap: een veilig verbond? Een onderzoek naar samenwerking, controle en (neven)effecten", Politiewetenschap, Sdu Uitgevers: Den Haag.

MacQueen, K. M., McLellan, E., Metzger, D. S., Kegeles, S., Strauss, R. P., Scotti, R., Blanchard, L. \& Trotter, R. T. (2001), What is community? An evidence-based definition for participatory public health. American journal of public health, 91(12), 1929-1938.

Mehlbaum, S. \& Van Steden, R. (2018), Doe-het-zelf-surveillance: Een onderzoek naar de werking en effecten van WhatsApp-buurtgroepen. Sdu.

Nabi, R. L. (2003), "Exploring the Framing Effects of Emotion:Do Discrete Emotions Differentially Influence Information Accessibility, Information Seeking, and Policy Preference?", Communication Research, Vol. 30, pp. 224-247.

Ohmer, M. and Beck, E. (2006), "Citizen participation in neighborhood organizations in poor communities and its relationship to neighborhood and organizational collective efficacy", Journal of Sociology and Social Welfare, Vol. 33, No. 1, pp. 179-202. 
Paton, D. (2013), "Disaster resilient communities: developing and testing an all-hazards theory", Journal of Integrated Disaster Risk Management, Vol. 3, pp. 1-17.

Paton, D., Bajek, R., Okada, N. and Mcivor, D. (2010), "Predicting community earthquake preparedness: a cross-cultural comparison of Japan and New Zealand", Natural Hazards, Vol. 54, pp. 765-781.

Paton, D. and Johnston, D. (2001), "Disasters and communities: vulnerability, resilience and preparedness" Disaster Prevention and Management: An International Journal, Vol. 10, pp. 270-277.

Paton, D., Okada, N. and Sagala, S. (2013), "Understanding preparedness for natural hazards: Cross cultural comparison" Journal of Integrated Disaster Risk Management, Vol. 3, pp. $18-35$.

Paton, D., Smith, L., Daly, M. and Johnston, D. (2008), "Risk perception and volcanic hazard mitigation: Individual and social perspectives", Journal of Volcanology and Geothermal Research, Vol. 172, pp. 179-188.

Pridmore, J., Mols, A., Wang, Y. and Holleman, F. (2018), "Keeping an eye on the neighbours: Police, citizens, and communication within mobile neighbourhood crime prevention groups", The Police Journal, pp. 1-24, DOI: 10.1177/0032258X18768397.

Ringle, C.M., Wende, S. \& Becker, J. (2015), SmartPLS 3. Bönningstedt: SmartPLS. Retrieved from http://www.smartpls.com

RIVM (2016), Nationaal veiligheidsprofiel. Available at: https://www.rivm.nl/documenten/nationaal-veiligheidsprofiel-2016 (accessed 12 January 2019).

Schreurs, W., Franjkić, N., Kerstholt, J. H., De Vries, P. W., \& Giebels, E. (2020), Why do citizens become a member of an online neighbourhood watch? A case study in The Netherlands. Police Practice and Research, 1-15.

Steg, L., Bolderdijk, J. W., Keizer, K. and Perlaviciute, G. (2014), "An Integrated Framework for Encouraging Pro-environmental Behaviour: The role of values, situational factors and goals", Journal of Environmental Psychology, Vol. 38, pp. 104-115.

Stoutland, S. E. (2001), "The multiple dimensions of trust in resident/police relations in Boston", Journal of research in crime and delinquency, Vol. 38, pp. 226-256.

Ter Huurne, E. and Gutteling, J. (2008), "Information needs and risk perception as predictors of risk information seeking", Journal of Risk Research, Vol. 11, pp. 847-862.

Terpstra, J. (2009), "Community policing in practice: ambitions and realization", Policing: A Journal of Policy and Practice, Vol. 4, pp. 64-72. 
Terpstra, T. (2011), Emotions, trust, and perceived risk: Affective and cognitive routes to flood preparedness behavior. Risk Analysis: An International Journal, 31(10), 1658-1675.

Tyler, T. R. and Fagan, J. (2008), "Legitimacy and cooperation: Why do people help the police fight crime in their communities", Ohio State Journal of Criminal Law, Vol. 6, pp. 231.

WABP. (2018), "WhatsApp Buurt Preventie Nederland [Online]". Available at": https://wabp.nl/. (accessed 21 November 2018).

Yetano, A., Royo, S. and Acerete, B. (2010), "What is driving the increasing presence of citizen participation initiatives?", Environment and Planning C: Government and Policy, Vol. 28, pp. 783-802. 